\title{
The Establishment and Analysis of Accident Control Model Based on Three-Dimensional Coordinates
}

\author{
Shen Zhuo ${ }^{1,2}$, Liu Danlong ${ }^{*}$, Luo Minggang $^{1}$ and Xiang Mingrui ${ }^{1}$ \\ ${ }^{I}$ China University of Mining and Technology, Beijing, 100083, P.R. China \\ ${ }^{2}$ National Institute for Occupational Safety, Beijing, 100029, P.R. China
}

\begin{abstract}
Through the analysis of previous theories about the cause of the accident, our study identified the main causes of accidents that are unsafe behaviors of human, unsafe conditions of objects and management factors. And the cause of an accident often is multifactorial not simply due to any one of the above three factors. Unsafe behavior of human, the unsafe condition of object, and management factors are taken as $\mathrm{X}, \mathrm{Y}$ and $\mathrm{Z}$ axis respectively. Keeping the main reason for the accident, interlaced relations among the main reason and the basic laws of security, the accident control model based on three-dimensional coordinates was established. By analyzing the safety factor, accident factor and synthesis factor in the model, the security of the system will be analyzed qualitatively and quantitatively.
\end{abstract}

Keywords: Accident-causing, accident control, model, safety, three-dimensional coordinates.

\section{INTRODUCTION}

The usual definition of Accident has been concluded as the thing, which is beyond people's expectation and causes loss, occurs all of a sudden [1]. The rate of social production has risen higher and higher, as the development of the technology and the social economy approach a new level, meanwhile. Meanwhile the enterprise has put more and more attention to the safety. As far as a corporation is concerned, once an accident occurs, it not only makes corporation suffer economic loss but also ruins the reputation of the enterprise. All these bad things result in the bad social influence, which is beyond people's evaluation. Therefore, research on the regulation of accident occurrence and how to prevent its occurrence and how to reduce the possibility of the accident's occurrence and how to minimize the damage and lengthen the period between two contiguous accidents has become researchers' hot spot.

Researchers at home and abroad have done a lot of research on accident causation theory, which are as follows:

At the beginning of $30 \mathrm{~s}$ in 20 century, Heinrich raised Heinrich's accidental chain model, which explains the accident as a result of a series of events based on the order of the time of every accident, which mainly include social environment, humans' mistake and unsafe behavior, and injuries and death, which belong to typical accidental causal chain theory [2]. Heinrich uses five dominoes to describe this relationship. If one of these dominoes is touched down, a series of things will happen, which may cause accident. If one of them is removed, the relationship will be destroyed, and the accident can be prevented [3].

*Address correspondence to this author at the China University of Mining and Technology, Beijing, 100083, P.R. China; Tel: 15201290604 ; Fax: 010-62339035; E-mail: 305618237@qq.com
At this foundation, the American ex-chief of Institute for international loss control, Frank Bird raised the modern accidental causal chain theory. Bird thought in spite of human's unsafe behavior and the unsafe condition of matters, the mistake of management should be the primary cause [4]. The British Prof. John Adams working in University of London raised a theory model similar to Bird's theory. Adams called human's unsafe behavior and the unsafe condition of matters as work place's mistake. Adams thought the primary cause of operator's mistake in work place result from management failure of providing good leadership and safety staff [5]. All these theories are related to casual theories.

Energy accidental release theory believes that accident's occurrence is due to abnormal and unexpected release of energy. We can control accident via controlling release of energy and carrier of energy [6]. In 1995, Prof. Chen Baozhi raised two hazard source theory based on systematic research on safety theory [7], which believed that the accident's occurrence is reaction result of two hazard sources. Prof. Fu Gui from China University of Mining and Technology, Beijing (cumtb), raised an organization safety management model, which thought organization's behavior decides individual's behavior. We can prevent accident via correcting organization's behavior [8].

\section{ANALYSIS ON ACCIDENT}

According to the cause of the accident, the total number of accidents caused by human mistake was about 70\% $90 \%$. In 1950s, 75000 accidents occurred in the United States, and in these accidents, human mistake accounted for $88 \%$. In Japan, in 1977, 104638 accidents occurred, which included manufacturing knock off for more than 4 days, the reason being human mistake that accounted for 94.5\% [9]. Nearly ten years statistics collected by American DuPont Co show that $96 \%$ of all accidents occurred in this corporation resulted from different kinds of unsafe behaviors [10]. All 
these statistics show that human's unsafe behaviors are the main reasons of an accident. Human beings are the actual participators and managements. Human's behaviors have something to do with safe production. Unsafe behavior such as worker's working against job regulation and conductor's conducting against regulation are often the direct reason resulting in accidents. Therefore, when it comes to controlling accident, we must take human's unsafe behaviors into consideration. Reducing or even removing human's unsafe behaviors does well for preventing accidents.

Unsafe environmental conditions have always been well accepted as the main reason to cause accident. Therefore, essentially safe equipment has been created as technology and material science developed. Essentially safe equipment means accident will not happen, even when incorrect operation or fault happens [11].

Both Bird's theory and Adams's theory believe that mistakes in management are the main reason that caused accidents. Statistics show that $80 \%$ of accidents have something to do with the management [12]. Therefore, the management's factor is also one of the main reasons causing accidents.

To sum up, unsafe behaviors of human and unsafe conditions of matter and management's factor are the main reason causing accidents. It is believed that these three aspects are closely linked. For example, for an accident caused by mistake, its reason cannot simply be concluded to be only due to human's unsafe behavior. Management's lack and even the faulty equipment may be the reason. This way all three aspects may be considered as participants of an accident. A safe measurement's conduction may help remove these factors whereas a dangerous measurement may enhance them.

\section{THREE-DIMENSIONAL COORDINATES ACCIDENT CONTROL MODEL}

\subsection{Model's Theoretical Basis}

(1) According to the last section, unsafe human behaviors, unsafe conditions of objects, and lack of management are the main factors causing accident.

A safe measurement's conduction may have a positive effect on all three aspects, not just only one aspect.

Murphy's law indicates that anything which is in fact possible, no matter how small the possibility is, can happen when get enough time. Event, which may cause accident, may be such a possibility followed by an accident that will occur sometime $[13,14]$. We can state this law in math formula as follow:

$\mathrm{P}_{\mathrm{n}}=1-(1-\mathrm{P})^{\mathrm{n}}$

$P$--possibility of some sudden thing, $(P>0)$;n--the time of possible thing's occurrence; $P_{n^{-}}$-the possibility of occurrence after the thing is repeated $\mathrm{n}$ times.

As you can see, however, $P$ is small when $n$ goes bigger and bigger, $P_{n}$ becomes closer and closer to 1 . This indicates that accident is inevitable. What can be done is to prevent the possibility and to reduce the loss of accident and to lengthen the period between two contiguous accidents.

\subsection{Three-Dimensional Coordinates Accident Control Model's Establishment}

Based on the theory of the main reason for the accident analysis and model building, according to the people's unsafe behavior, unsafe condition and management factors, we established the security state of the system of threedimensional coordinate safety management model (Fig. 1). The model takes the unsafe human behavior as the $\mathrm{X}$ axis, and the unsafe state of the material as $\mathrm{Y}$ axis, the management factor as $Z$ axis. The zero indicates the absolute safety state. The space is composed of $X>0, Y>0, Z>0$, which is called dangerous space which is short for $D$. We name the point as accident factor which is short for $\mathrm{d}$. The space composed of $\mathrm{X}<0, \mathrm{Y}<0, \mathrm{Z}<0$ which is called for safe space short for $\mathrm{S}$. And we call the space point as safety factor short for $\mathrm{s}$. The distance between the accident factor and zero is called the accident scale dl. The distance between the safety factor and the zero is called the safety scale sl. The values of the incident scale are gradually increasing along the $\mathrm{X}, \mathrm{Y}$ and $\mathrm{Z}$ axes, while the values of the safe scale are gradually decreased along the $\mathrm{X}, \mathrm{Y}$ and $\mathrm{Z}$ axis, and their absolute values are gradually increased.

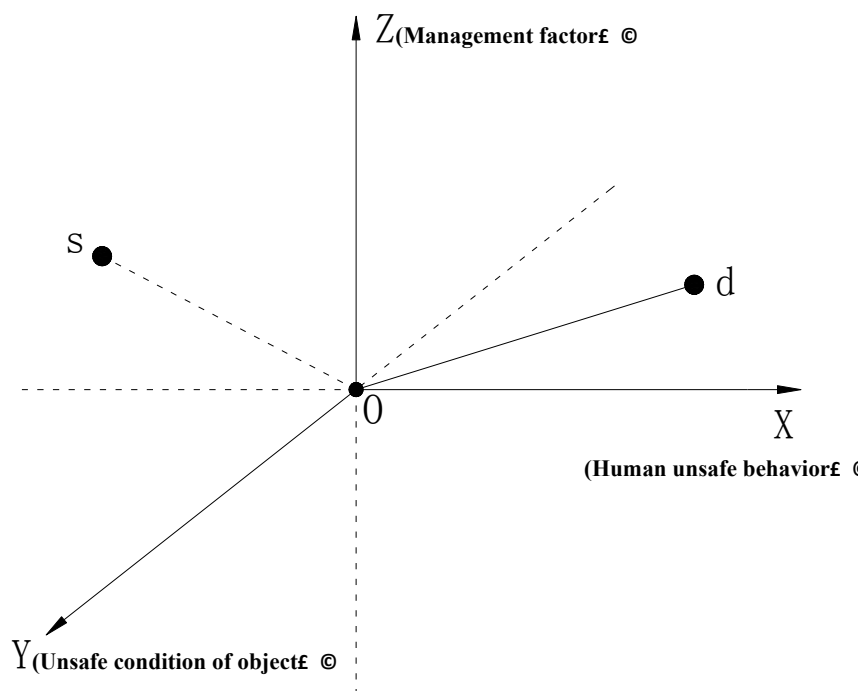

Fig. (1) Three-dimensional coordinates accident control model.

\subsection{Analysis of the Three-Dimensional Coordinates Accident Control Model}

The safety factors in the model indicate that all methods and means can improve system security and suppress accidents. For example, the replacement of advanced equipment, strengthen management systems and so on are safety measures. When the safety factor is located at X, Y or $\mathrm{Z}$ negative axle, it represents that the safety factor only belongs to any one of the human behavior, condition, or management factors, such as the replacement of advanced equipment just belong to the aspect of condition of object, it 
should be located in Y negative axle. However, according to the basic theory (2) of the model, there are many safety factors that do not simply belong to one of the three kinds of security factors, but are associated with a variety of factors. When safety factors are in the negative plane circled by $X$ and $\mathrm{Y}, \mathrm{Y}$ and $\mathrm{Z}$, or $\mathrm{X}$ and $\mathrm{Z}$ or in the space named $\mathrm{S}$ constituted by $\mathrm{X}, \mathrm{Y}$ and $\mathrm{Z}$, safety factors indicate that the contents contain two or three of human behavior, the state of matter and management factors, these safety factors can improve the security status of people, goods, and management simultaneously. The projected length of its security dimension on $\mathrm{X}, \mathrm{Y}, \mathrm{Z}$ axis represents the component size of people, objects and management (Fig. 2).

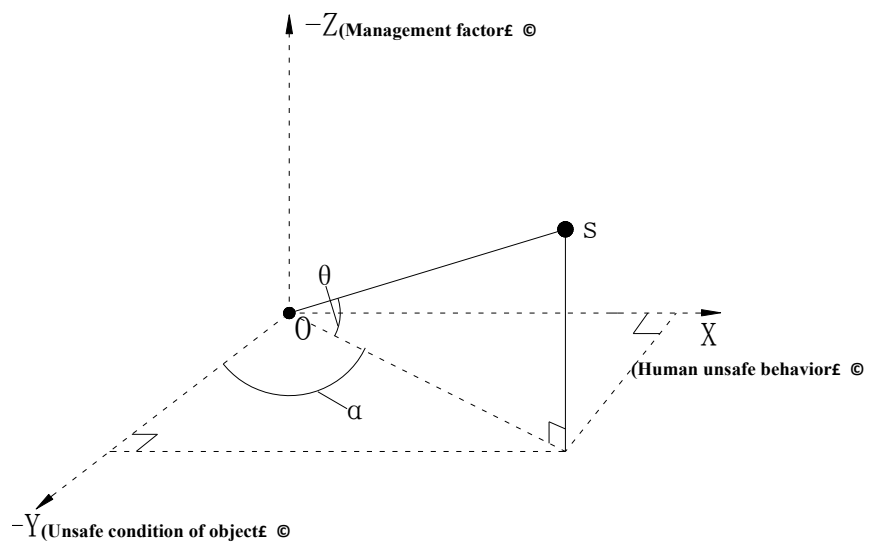

Fig. (2). Safety factor analysis.

where

$\left\{\begin{array}{l}s l_{z}=s l \times \sin \theta \\ s l_{y}=s l \times \cos \theta \times \cos \alpha \\ s l_{x}=s l \times \cos \theta \sin \alpha\end{array}\right.$

$s l_{z} \_$a safety factor ' security dimension component size on Z-axis.

$s l_{y} \longrightarrow$ a safety factor ' security dimension component size on Y-axis.

$s l_{x} \longrightarrow$ a safety factor ' security dimension component size on X-axis.

$\theta$ _-Angle between a safety factor and Z- negative axle.

$\alpha$-Angle between $\mathrm{Y}$ - negative axle and a projection of safety factor on XOY plane.

Accident factors represent the potential risk factors which can cause accidents, such as the illegal operations. Similar to the safety factors, when an accident factor is located on $\mathrm{X}$, $\mathrm{Y}$, or Z-positive axle, it indicates that the accident factor only belongs to any one of the human unsafe acts, unsafe conditions or management factors. When accident factors are in the positive plane circled by $\mathrm{X}$ and $\mathrm{Y}, \mathrm{Y}$ and $\mathrm{Z}$, or $\mathrm{X}$ and $\mathrm{Z}$ or in the space named $\mathrm{D}$ constituted by $\mathrm{X}, \mathrm{Y}$ and $\mathrm{Z}$, accident factors indicate the contents contain any two or three of human unsafe behavior, unsafe condition of object and management factors blended. The projected length of its accident dimension in $\mathrm{X}, \mathrm{Y}, \mathrm{Z}$ axis represents the component size of people, objects and management (Fig. 3).

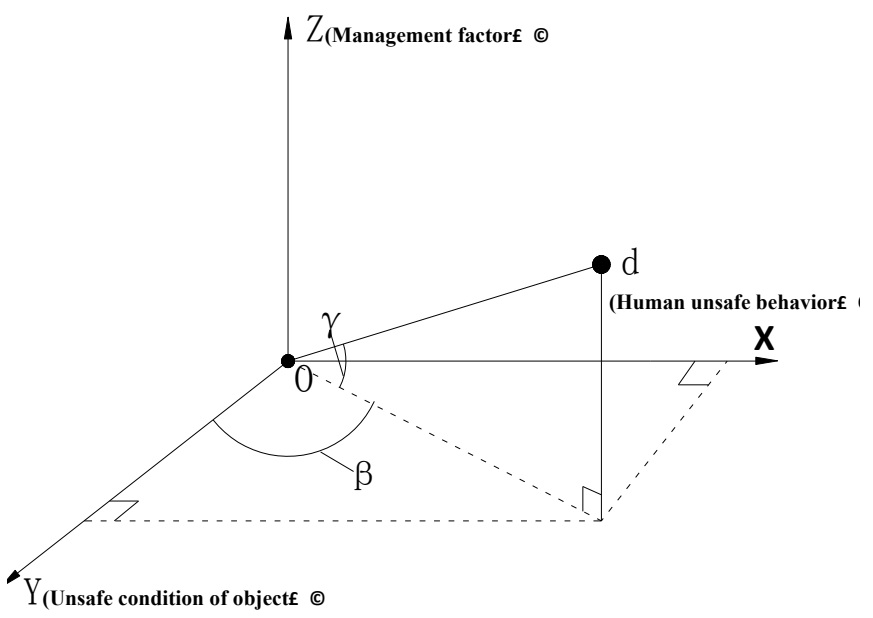

Fig. (3) Accident factor analysis.

$\left\{\begin{array}{l}d l_{z}=d l \times \sin \gamma \\ d l_{y}=d l \times \cos \gamma \times \cos \beta \\ d l_{x}=d l \times \cos \gamma \sin \beta\end{array}\right.$

$d l_{z} \longrightarrow$ an accident factor 's dimension component size on Z-axis.

$d l_{y} \_$an accident factor 's dimension component size on $\mathrm{Y}$-axis.

$d l_{x}=$ an accident factor 's dimension component size on $\mathrm{X}$-axis.

$\gamma$-Angle between an accident factor and Z- positive axle.

$\beta$-Angle between $\mathrm{Y}$ - positive axle and a projection of accident factor on XOY plane.

\subsubsection{The Dangerous Classification in the Model}

In the model, the modulus of vectors of all accident factors minus the modulus of vectors of all safety factors is the synthesis factor represented by C. Synthesis factor C represents the security status of the system.

All modulus of vectors of accident factors $<10$, Synthesis factor $\mathrm{C}>0$. According to synthesis factor $\mathrm{C}$, the system can divide hazard level, as shown in Table $\mathbf{1 .}$

Table 1. Hazard ratings list.

\begin{tabular}{|c|c|}
\hline C & Hazard Level \\
\hline \hline$(0,1]$ & Relatively safe \\
\hline$(1,3]$ & Low risk \\
\hline$(3,7]$ & Intermediate risk \\
\hline$(7,10]$ & High risk \\
\hline$(10,10+)$ & Serious risk \\
\hline
\end{tabular}

NOTE: The size of the accident factors and safety factors are determined based on the actual situation of the system. The basic principles are according to the influence of the accident factors or safety factors on the security of the system to determine the size. 


\subsubsection{Synthesis Factor Calculation}

$\left|\sum_{i=1}^{n} \vec{s}_{i}\right|=\left[\begin{array}{l}\left(\sum_{i=1}^{n} s l_{i} \sin \theta_{i}\right)^{2}+\left(\sum_{i=1}^{n} s l_{i} \cos \theta_{i} \cos \alpha_{i}\right)^{2} \\ +\left(\sum_{i=1}^{n} s l_{i} \cos \theta_{i} \sin \alpha_{i}\right)^{2}\end{array}\right]^{\frac{1}{2}}$

$\left|\sum_{j=1}^{m} \vec{d}_{j}\right|=\left[\begin{array}{l}\left(\sum_{j=1}^{m} d l_{j} \sin \gamma_{j}\right)^{2}+\left(\sum_{j=1}^{m} d l_{j} \cos \gamma_{j} \cos \beta_{j}\right)^{2} \\ +\left(\sum_{j=1}^{m} d l_{j} \cos \gamma_{j} \sin \beta_{j}\right)^{2}\end{array}\right]^{\frac{1}{2}}$

$C=\left|\sum_{j=1}^{m} \vec{d}_{j}\right|-\left|\sum_{i=1}^{n} \overrightarrow{s_{i}}\right|$

$\mathrm{C}$ - Synthesis factor

$n-$ Number of safety factors

$m-$ Number of accident factors

$\theta$ _-Angle between a safety factor and Z- negative axle.

$\alpha$-Angle between $\mathrm{Y}$ - negative axle and a projection of safety factor in XOY plane.

$\gamma$-Angle between an accident factor and Z- positive axle.

$\beta$ _ Angle between Y-positive axle and a projection of accident factor in XOY plane.

Thereby, the size of synthesis factor will be calculated, which can quantitatively analyze the security status of the system.

\section{MODEL APPLICATION}

On December 27, 2009, at Changsha City, Hunan Province, "Shanghai City" construction site, an elevator fall accident occurred while transporting construction workers. It killed 18 people, one seriously injured.

The accident was analyzed by the based on threedimensional coordinates accident control model:

(1) Safety factor:

$\mathrm{s}_{1}\left(\mathrm{sl}_{1}=2, \theta_{1}=90^{\circ}, \alpha_{1}=0\right):$ Civil engineering supervision arrangement

(2) Accident factors:

$\mathrm{d}_{1}:\left(\mathrm{dl}_{1}=3, \gamma_{1}=60^{\circ}, \beta_{1}=0\right)$ : Failing acceptance.

$\mathrm{d}_{2}:\left(\mathrm{dl}_{2}=5, \gamma_{2}=11.5^{\circ}, \beta_{2}=45^{\circ}\right)$ : Elevator standard section bolt is not required to install.

$\mathrm{d}_{3}:\left(\mathrm{dl}_{3}=2, \gamma_{3}=30^{\circ}, \beta_{3}=90^{\circ}\right)$ : Overloading

$\mathrm{d}_{4}:\left(\mathrm{dl}_{4}=2, \gamma_{4}=0, \quad \beta_{4}=90^{\circ}\right)$ : Elevator installers without practicing certificate.

$\mathrm{d}_{5}:\left(\mathrm{dl}_{5}=3, \gamma_{5}=30^{\circ}, \beta_{5}=90^{\circ}\right)$ : Person in charge of the site unexamined. $\mathrm{d}_{6}:\left(\mathrm{dl}_{6}=2, \gamma_{6}=0, \beta_{6}=90^{\circ}\right)$ : Supervisory staff did not perform the duty.

$\mathrm{d}_{7}:\left(\mathrm{dl}_{7}=2, \quad \gamma_{7}=45^{\circ}, \quad \beta_{7}=90^{\circ}\right)$ : Security staff was not arranged to manage site security.

$\mathrm{d}_{8}:\left(\mathrm{dl}_{8}=3, \gamma_{8}=45^{\circ}, \quad \beta_{8}=90^{\circ}\right)$ : Corporate representatives privately hired staff without practicing certificate.

(3) Calculating Synthesis factor (C)

According to Formula 2 6:

Result: $\mathrm{C}=16.8>10$, according to Hazard Level Table, the elevator was at serious risk level. Human unsafe behavior is the first important factor of the accident; management is the second; and the unsafe condition of object is the third. So, the accident is within the expected.

$\sum_{i=1}^{n=1} s l_{z(\mathrm{i})}=2$

$\left|\sum_{i=1}^{n=1} \overrightarrow{s_{i}}\right|=2$

$\sum_{j=1}^{m=8} d l_{\mathrm{z}(j)}-\sum_{i=1}^{n=1} s l_{\mathrm{Z(i)}}=7.6$

$\left|\sum_{j=1}^{m=8} \vec{d}_{j}\right|=18.8$

$\sum_{j=1}^{m=8} d l_{x(j)}=15.3$

$\sum_{j=1}^{m=8} d l_{z(j)}=9.6$

$\sum_{j=1}^{m=8} d l_{y(j)}=5.0$

$C=\left|\sum_{j=1}^{m=8} \overrightarrow{d_{j}}\right|-\left|\sum_{i=1}^{n=1} \overrightarrow{s_{i}}\right|=16.8$

\section{CONCLUSION}

(1) Combining with previous analyses for accident causing theory and statistics, it has been established that the main reasons for accidents are unsafe behaviors of human, unsafe conditions of objects and management factors.

The relationship among human unsafe acts, unsafe conditions of object and management is intertwined, that is implementing security measures for avoiding accidents might have a positive impact on all three aspects i.e. people, goods and management, rather than simply one of them.

(3) According to the main reasons of accident drawn from the analysis, the accident control model includes human unsafe acts, unsafe conditions of object, and management factors as axis. This model can 
qualitatively and quantitatively analyze system security.

(4) Based on the elevator falling accident mentioned above, application of the model listed safety factors and accident factors of the elevator; and according to the formula given in the model calculated the size of its dangers.

\section{CONFLICT OF INTEREST}

The authors confirm that this article content has no conflict of interest.

\section{ACKNOWLEDGEMENTS}

Declared none.

\section{REFERENCES}

National registered safety engineer qualification examination counseling Textbook Compilation Committee. Knowledge of Safety Production Management. Beijing: Coal Industry Press, 2004, pp. 3-5.

[2] X. Sun, X. Zhou, J. Lin, and J. Yang, "Research on development and application of accident model theory," Quality and Reliability, vol. 2 pp. 19-23, 2014

[3] M. Zhong, Y. Wei, W. Fan, and Q. Wang, "Overview on AccidentCausing Theories," Fire Science, vol. 3, pp. 38-44, 1999.
[4] C. Luo, and X. Xie, "Comparison study of Accident-Causing Theories," China Safety Production Science and Technology, vol. 5, pp. 111-115, 2007.

[5] R. Qin, and D. Peng, "Discuss of the Accident -Causing Theory," Journal of North China Institute of Science and Technology, vol. 3, pp. 1-10, 2005.

[6] Q. Chen, "Analysis on Accident Causation Factors and Hazard Theory," Chinese Journal of Safety Science China Safety Science, vol. 10 , pp. 67-71, 2009

[7] B. Chen, "Hazard Identification and Control and Evaluation," Chengdu: Sichuan science and Technology Press, 1996.

[8] G. Fu, B. Lu, and X. Chen, "Behavior Based Model for Organizational Safety Management," Chinese Journal of Safety Science, vol. 9, pp. 21-27, 2005.

[9] D. Yang, "Analysis on the Cause of Human Errors and Study on the Preventive Countermeasures," Chinese Journal of Safety Science, vol. 2, 1997.

[10] Y. Liu, and S. Shi, "Behavior Motivation Mechanism in Coal mine Accident Prevention," Chinese Journal of Safety Science, vol. 2, pp. 85-91, 2009

[11] J. Tao, "On Essential Safety," Chinese Journal of Safety Science, vol. 5, pp. 4-11, 2000 .

[12] Q. Wu, and K. Xu, "Safety Management Science," Beijing: Coal Industry Press, 2002.

[13] Q. Cui, S. Huang, and G. Li, "On alert security management functions - Murphy's Law Implications," China Safety Science, vol. 4, pp. 21-23, 1999.

[14] H. Wang, Q. Ye, Y. Pi, and Y. Tan, "Murphy's Law in Coal Mine Safety Management," Mining Engineering, vol. 1, pp. 44-47, 2014.

(C) Zhuo et al.; Licensee Bentham Open.

This is an open access article licensed under the terms of the (https://creativecommons.org/licenses/by/4.0/legalcode), which permits unrestricted, non-commercial use, distribution and reproduction in any medium, provided the work is properly cited. 